\title{
Effect of Comprehensive Dental Rehabilitation on Growth Parameters in Pediatric Patients with Severe Early Childhood Caries
}

\author{
1Jayna Sachdev, ${ }^{2}$ Kalpana Bansal, ${ }^{3}$ Radhika Chopra
}

\begin{abstract}
Background: Children who have severe early childhood caries (S-ECC) weigh significantly less than caries-free children. The association between S-ECC and weight suggests that its timely treatment at early stages may preserve general health, in addition to preventing pain and infection.
\end{abstract}

Objective: This study was conducted to evaluate whether children with untreated S-ECC had lower weight and height as compared with children with low caries and to evaluate whether full mouth rehabilitation of children with S-ECC resulted in the phenomenon of catch-up growth.

Materials and methods: The weight and height of children with noncontributory medical histories and S-ECC (3-6 years) were compared with caries-free children, before and 6 months after full mouth dental rehabilitation.

Results: Prior to dental rehabilitation, children with S-ECC had significantly less weight and height than their comparison counterparts $(p<0.001)$. Following therapeutic intervention, the test group children exhibited catch-up growth in relation to weight, as there was no significant difference in the body weight of the test and control groups $(p=0.171)$.

Conclusion: Comprehensive full mouth rehabilitation of children with S-ECC results in catch-up growth, thus improving the overall health of the child.

Keywords: Catch-up growth, Height, Rehabilitation, S-ECC, Weight.

How to cite this article: Sachdev J, Bansal K, Chopra R. Effect of Comprehensive Dental Rehabilitation on Growth Parameters in Pediatric Patients with Severe Early Childhood Caries. Int J Clin Pediatr Dent 2016;9(1):15-20.

Source of support: Nil

Conflict of interest: None

\section{${ }^{1}$ Ex-Postgraduate Student, ${ }^{2}$ Professor and Head, ${ }^{3}$ Reader}

1,2Department of Pedodontics and Preventive Dentistry, SGT Dental College, Hospital and Research Institute, Gurgaon Haryana, India

${ }^{3}$ Department of Pedodontics and Preventive Dentistry, ITS Centre for Dental Studies and Research, Ghaziabad, Uttar Pradesh, India

Corresponding Author: Jayna Sachdev, H. No. 165 Siddhartha Enclave, Ashram Chowk, New Delhi-110014, India Phone: 09910866055, e-mail: jaynasachdev@gmail.com

\section{INTRODUCTION}

Oral health is an essential component of total health and well-being. Despite increase in the availability of caries preventive measures, such as fluoride dentifrices and mouth washes, dental caries still continues to be highly prevalent in the early childhood period. ${ }^{1,2}$ Early childhood caries (ECC) has been defined as "the presence of one or more decayed (noncavitated or cavitated lesions), missing (due to caries), or filled tooth surfaces" in any primary tooth in a child under the age of 6 years. ${ }^{3}$ Severe early childhood caries (S-ECC) is defined as any sign of smooth surface caries in children under 3 years of age. From ages 3 through 5 years, one or more cavitated, missing (due to caries) or filled smooth surfaces in primary maxillary anterior teeth or a decayed, missing or filled score of $\geq 4$ (age 3 years), $\geq 5$ (age 4 years) or $\geq 6$ (age 5 years) surfaces constitutes S-ECC. ${ }^{3}$

Dental caries continues to be a major health problem in the developing nations because of the lack of education and awareness and poor socioeconomic status. ${ }^{4-6}$ Socioeconomic status influences the nutrition and access for health care services. ${ }^{7}$ In the developing nations children suffer from a dual risk of malnutrition, with obesity in those living in urban areas and undernutrition in children from rural and slum areas. ${ }^{8}$ Recently, the United Nations International Children's Emergency Fund reported that about 146 million children below 5 years of age were underweight. ${ }^{9}$

The potential impact of S-ECC on the general health and development has been widely reported in the literature. On a population basis, it has been observed that with advancing age, and presumably increasing severity of ECC, there was a deceleration of weight gain such that older children with nursing caries were more likely to be represented by lower weight percentile categories. ${ }^{10}$ Furthermore, dental interventions in ECC children had a significant positive impact on parental ratings of their overall oral health and physical, mental and social functioning. ${ }^{11}$ The greatest improvement was noted in pain experience followed by improved abilities to eat and sleep along with parental satisfaction. ${ }^{12}$ The phenomenon of catch-up growth has been reported to occur in children, whose growth had 
been slowed down by malnutrition following complete dental intervention. ${ }^{10}$

The prevalence of ECC in children in the rural regions of Haryana is very high, ${ }^{13,14}$ hence the present study was planned, firstly, to determine if young children with S-ECC with nonsignificant medical histories (absence of systemic illness) that receive complete dental treatment have less weight and height preoperatively compared with age- and sex-matched low caries children and, secondly, whether full mouth rehabilitation of these patients can bring their weight and height measures comparable to those of low caries children and they demonstrate a phenomenon of catch-up growth by growth velocity calculation.

\section{MATERIALS AND METHODS}

This case-control follow-up study was carried out in the Department of Pedodontics and Preventive Dentistry, Shree Guru Gobind Singh Tricentenary (SGT) Dental College, Gurgaon, Haryana, India. The study was reviewed and approved by the Ethical Committee of SGT Dental College, Gurgaon. Informed consent was taken from parents or legal guardians prior to patient enrolment in the study.

A total of 80 children within the age range of 3-6 years from low socioeconomic status families, who visited the Department of Pedodontics, were included in the study. The children who were physically and mentally compromised, were on medications and had undergone prior invasive dental treatment (extractions or restorations) were excluded from the study. The included children were divided into two equal groups: test and control groups. The test group $(n=40)$ included children with minimum of four severely decayed teeth with at least two teeth that had pulpal involvement. Children having less than or equal to three enamel or dentinal carious lesions without pulpal involvement formed the control group $(n=40)$. The pulpal involvement was detected clinically and confirmed radiographically. Both the groups had similarly matched age, gender and socioeconomic status.

Baseline data included recording of decayed, extracted and filled teeth (deft index) followed by the anthropometric measurements height $(\mathrm{Ht})$ in centimeters, weight $(\mathrm{Wt})$ in kilograms. Caries status of the child was recorded using deft index. ${ }^{15}$ Weight and height measurements were taken for each child dressed in light clothes and no shoes. Height was measured using a wall-mounted stadiometer and weight using standard weighing machine after calibration. ${ }^{5}$

After recording the preliminary data, complete dental rehabilitation of S-ECC children was performed according to individual needs. The complete dental treatment included restorations, pulp therapies, extractions if required followed by space management in routine dental setting over multiple visits. The number of visits depended upon the caries status and the child's cooperation. The child and parents were also given educational preventive counseling for dental health.

After complete dental rehabilitation, the children were recalled for a follow-up visit after a period of 6 months. The anthropometric measurements were repeated at the 6-month recall visit following the completed dental treatment. The growth velocity, a mathematically derived measurement, by convention, is expressed in terms of growth per 6-month period. ${ }^{6}$ It was calculated as follows ${ }^{16}$ :

Growth velocity per month for weight (weight/height velocity) can be calculated as:

$$
\frac{\text { Weight/Height (follow-up visit) - }}{\text { Weight/Height (initial visit) }}
$$

\section{STATISTICAL ANALYSIS}

The statistical analysis was done using Statistical Package for the Social Sciences (SPSS) version 19.0 computer software (SPSS Inc, Chicago, IL, USA). One sample t-test was used to analyze the differences in height and weight of the test group preoperatively as compared with age- and sex-matched caries-free children. The growth velocities in the test and control groups were compared using independent sample t-test. Associations and differences were considered significant when the $p$ value was $<0.05$.

\section{RESULTS}

A total of 80 subjects (40 test and 40 control) meeting the inclusion criteria were enrolled in the study. Both the groups consisted of 30 boys and 10 girls each. Of them, 15 were excluded from the test group due to incomplete treatment or loss of follow-up; hence, there were a total of 25 patients in the test group during follow-up. We included 25 patients randomly from the control group for statistical evaluation. The test and control subjects were still age- and sex-matched after the sample was reduced. The mean age in both the groups was 4.57 years. The follow-up length for the test group ranged from a minimum of 6 months, extending up to 8 months with an average being 6.6 months, whereas for the control group the follow-up length was 6.5 months.

\section{Comparison between Mean Values of Baseline Anthropometric Measurements of Control and Test Groups}

At, baseline the test group children $(n=40)$ had a weight of $13.96 \pm 2.20 \mathrm{~kg}$ as compared with $15.80 \pm 1.37 \mathrm{~kg}$ in the 
control group $(n=40)$, the difference being statistically significant $(p<0.001)$. Similarly, a statistically significant difference was seen in relation to height $(p=0.002)$, the test group $(n=40)$ children having a mean height of 101.07 $\pm 6.71 \mathrm{~cm}$ with the control group $(\mathrm{n}=40)$ having a mean height of $105.43 \pm 5.43 \mathrm{~cm}$. Also, a statistically significant difference was seen in the deft status $(\mathrm{p}<0.001)$ among the test and the control groups as depicted in Table 1.

For 50 children who were available for follow-up, the baseline statistics were:

- Test group ( $\mathrm{n}=25)$ : mean weight was $14.24 \pm 2.30 \mathrm{~kg}$ and mean height was $101.68 \pm 7.40 \mathrm{~cm}$.

- Control group ( $\mathrm{n}=25)$ : mean weight was $15.76 \pm 1.42 \mathrm{~kg}$ and mean height was $106.93 \pm 5.20 \mathrm{~cm}$.

The difference between test and control groups at baseline was statistically significant $(\mathrm{p}<0.001)$.

\section{Comparison between Mean Values of Follow-up Anthropometric Measurements of Control and Test Groups}

From Table 2, it is evident that no statistically significant difference $(\mathrm{p}=0.171)$ was seen in relation to weight between test $(16.96 \mathrm{~kg})$ and control groups $(17.78 \mathrm{~kg})$ at the followup visit, as compared with the baseline values, depicting a phenomenon of catch-up growth in the test group subjects

Table 1: Comparison between mean values of baseline anthropometric measurements of control and test groups

\begin{tabular}{|c|c|c|c|c|c|c|}
\hline & Group & $N$ & Mean & $\begin{array}{l}\text { Standard } \\
\text { deviation }\end{array}$ & $\begin{array}{l}t- \\
\text { value }\end{array}$ & $\begin{array}{l}p- \\
\text { value }\end{array}$ \\
\hline \multirow[t]{2}{*}{ Age (years) } & Test & 40 & 4.48 & 0.68 & 1.28 & 0.204 \\
\hline & Control & 40 & 4.65 & 0.53 & & \\
\hline \multirow[t]{2}{*}{ Height $(\mathrm{cm})$} & Test & 40 & 101.07 & 6.71 & 3.2 & 0.002 \\
\hline & Control & 40 & 105.43 & 5.43 & & \\
\hline \multirow[t]{2}{*}{ Weight (kg) } & Test & 40 & 13.96 & 2.2 & 4.49 & $<0.001$ \\
\hline & Control & 40 & 15.8 & 1.37 & & \\
\hline \multirow[t]{2}{*}{ Deft (N) } & Test & 40 & 7.95 & 2.22 & 19.9 & $<0.001$ \\
\hline & Control & 40 & 0.63 & 0.7 & & \\
\hline
\end{tabular}

Table 2: Comparison between mean values of follow-up anthropometric measurements of control and test groups

\begin{tabular}{lllllll}
\hline & & & \multicolumn{5}{c}{ Standard } & $t$ - & $p$ - \\
& Group & $N$ & Mean & deviation & value & value \\
\hline Height $(\mathrm{cm})$ & Test & 25 & 106.99 & 7.56 & 3.185 & 0.003 \\
& Control & 25 & 112.81 & 5.15 & & \\
Weight $(\mathrm{kg})$ & Test & 25 & 16.96 & 2.48 & 1.391 & 0.171 \\
& Control & 25 & 17.78 & 1.59 & & \\
Weight & Test & 25 & 2.72 & 0.63 & 3.761 & $<0.001$ \\
difference* $^{*}$ & Control & 25 & 2.02 & 0.68 & & \\
Height $_{\text {difference }}$ & Test & 25 & 5.31 & 1.52 & 1.145 & 0.258 \\
Age (years) & Control & 25 & 5.88 & 1.98 & & \\
& Test & 25 & 4.4 & 0.76 & 1.044 & 0.302 \\
& Control & 25 & 4.6 & 0.58 & & \\
\hline
\end{tabular}

*Weight and height difference $=$ Follow-up value - Baseline value

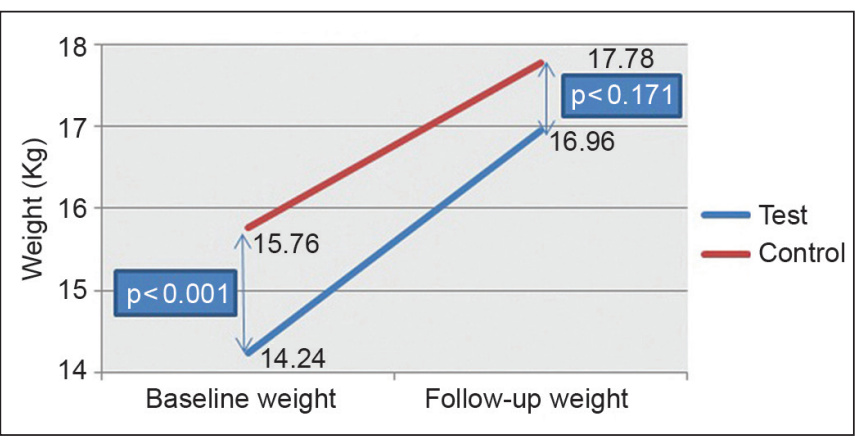

Graph 1: Comparison between baseline and follow-up weight in the test and control groups

(Graph 1). However, there was a statistically significant difference $(p=0.003)$ between the follow-up height of the test $(106.99 \mathrm{~cm})$ and control groups $(112.81 \mathrm{~cm})$, indicating no catch-up growth in terms of height. A statistically significant difference was also seen between the difference in weight (weight at follow-up minus weight at baseline) when comparing the test $(2.72 \mathrm{~kg})$ and the control groups $(2.02 \mathrm{~kg}$ ) with a p-value of $<0.001$, indicating more weight gain in the test subjects than in the control subjects. However, no statistically significant difference was seen between the height difference $(p=0.258)$ and also in relation to age $(p=0.302)$ among both the groups.

\section{Comparison between the Growth Velocity and Growth Velocity Percentage in the Test and Control Groups in Terms of Height and Weight}

The weight velocity for the test group came out to be $0.41 \mathrm{~kg} /$ month and for the control group to be $0.31 \mathrm{~kg} /$ month, demonstrating a highly statistically significant difference $(\mathrm{p}=0.001)$, thus depicting the phenomenon of catch-up growth in the test group (Table 3). In terms of weight velocity percentage (postoperative weight minus preoperative weight divided by initial weight and then multiplied by 100) also, statistically significant difference was obtained $(p=0)$. However, no statistically significant difference was seen in terms of height velocity $(p=0.313)$ and height velocity percentage (postoperative height minus preoperative height divided by initial height and then multiplied by 100) $(p=0.576)$ comparing the test and control groups, showing that the test children could not catch up with the control children when height was taken as a growth measure.

\section{DISCUSSION}

Early childhood caries has been recognized as an infectious and transmissible childhood disease with long-term growth and developmental implications. ${ }^{17}$ The concept that dental disease and child's body weight may be related 
Table 3: Comparison between the growth velocity and growth velocity percentage in the test and control groups in terms of height and weight

\begin{tabular}{lllllll}
\hline $\begin{array}{l}\text { Growth } \\
\text { velocity }\end{array}$ & Group & $N$ & Mean & $\begin{array}{l}\text { Standard } \\
\text { deviation }\end{array}$ & $\begin{array}{l}t- \\
\text { value }\end{array}$ & $\begin{array}{l}p \text { value } \\
\text { veight }\end{array}$ \\
Test & 25 & 0.41 & 0.09 & 3.67 & 0.001 \\
velocity & Control & 25 & 0.31 & 0.11 & & \\
Weight & Test & 25 & 19.49 & 5.03 & 4.82 & 0 \\
velocity \% & Control & 25 & 12.91 & 4.61 & & \\
Height & Test & 25 & 0.82 & 0.28 & -1.02 & 0.313 \\
velocity & Control & 25 & 0.9 & 0.3 & & \\
Height & Test & 25 & 5.25 & 1.59 & -0.56 & 0.576 \\
velocity \% & Control & 25 & 5.53 & 1.92 & & \\
\hline
\end{tabular}

was raised as early as 1982, when a retrospective casenote study that examined the body weights of children coming for tooth extractions under general anesthesia were compared with children coming for routine dental care, ${ }^{18}$ and subsequent studies have suggested that treatment of caries may lead to improvement in weight, gain ${ }^{10,19}$ at least in children whose weight is below average. ${ }^{20}$

The above-mentioned association between dental caries and children's weights is based on the fact that the manifestations of untreated ECC may go beyond pain and infection and the condition may also affect the general health. ${ }^{10,21}$ Consequences of untreated ECC include a higher risk of new carious lesions in both the primary and permanent dentitions, hospitalizations and emergency room visits, increased treatment costs, risk for delayed physical growth and development, loss of school days and increased days with restricted activity, diminished ability to learn and diminished oral health-related quality of life. ${ }^{3}$ Dental treatment also makes a very significant difference to the psychological and social aspects of the child's life. ${ }^{12,22-25}$ These improvements include less pain and improved abilities to eat and sleep.

The results of our study show a significant correlation between untreated dental caries and decreased body weight. The test group subjects weighed significantly less $(p<0.001)$ than the control group at baseline. Also, there was a highly statistically significant difference $(p=0.002)$ between the height of test and control groups, the test subjects being shorter than control subjects at baseline. Our findings corroborated with those of Miller et al $^{18}$ who obtained similar results where 1,105 children who required extractions were significantly lighter than the weights of 527 children who did not require dental extractions. Acs et $\mathrm{al}^{21}$ showed that 3-year-old with nursing caries with at least one pulpally involved tooth weighed about $1 \mathrm{~kg}$ less than control children without nursing caries. Ayhan et $\mathrm{al}^{26}$ also concluded that ECC children had lower mean weight than those of caries-free comparisons, thereby suggesting that
ECC children had inadequate caloric consumption. Gaur and Nayak ${ }^{5}$ also compared the height and weight of children with S-ECC and caries-free children. They found that mean height and weight of the S-ECC group was less as compared with that of the caries-free control group.

There are at least three highly plausible mechanisms for how dental caries may be associated with underweight and poor growth in young children. First, untreated caries and associated infection can cause pain and discomfort and reduce intake of foods because eating is painful. ${ }^{10,27}$ Second, severe caries can affect children's quality of life and thereby growth. Impacts include pain, irritability and disturbed sleeping habits. ${ }^{22,27}$ Disturbed sleep may affect glucosteroid production and growth. Untreated dental caries significantly impacts on the quality of life of children and their dietary intake. ${ }^{22,24}$ The consequences of high caries levels also include a higher risk of hospitalizations and emergency dental visits, increased days with restricted activity and absence from school and a diminished ability to learn. ${ }^{27} \mathrm{~A}$ third possible mechanism of how untreated severe caries with pulpitis affects growth is that chronic inflammation from pulpitis and chronic dental abscesses affect growth via chronic inflammation affecting metabolic pathways where cytokines affect erythropoiesis. For example, interleukin-1 (IL-1), which has a wide variety of actions in inflammation, can induce inhibition of erythropoiesis. This suppression of hemoglobin can lead to anemia of chronic disease as a result of depressed erythrocyte production in the bone marrow. ${ }^{27,28}$

Growth velocity is expressed in terms of growth per 6-month period. Growth velocity is studied to show how much growth varies at various ages, what patterns of growth are revealed and what they can tell us about the growth of pediatric patients. For velocity information, a longitudinal method is necessary by which the same individuals are measured at specific ages over a period of time. Thus, incremental measures are sought. The improved velocity rates are depictive of periods of catch-up growth. $^{29}$

Healthy children establish and follow a stable velocity growth curve for weight and height. Various insults, including nutritional deficiencies, may deflect children from their normal growth curve temporarily. With correction of these conditions, children will usually exhibit "catch-up growth", rising initially above before falling back onto the established growth curve. ${ }^{23}$

In terms of growth velocity, the difference was highly statistically significant $(p=0.001)$ in terms of weight velocity and weight velocity percentage $(p=0)$ in this study, thus depicting the phenomenon of catch-up growth in the test group. However, no statistically 
significant difference was seen in terms of height velocity $(p=0.313)$ and height velocity percentage $(p=0.576)$ comparing the test and control groups.

After dental rehabilitation, the test group subjects showed a significant increase in weight in this study, which is similar to that reported in earlier studies. $5,10,20$ The catch-up growth observed in the test patients following complete dental rehabilitation suggests that untreated ECC was responsible for the age-adjusted weight differences between the two groups. Following complete dental rehabilitation of children with S-ECC, there was no longer any statistical difference $(p=0.171)$ in their age-adjusted weights when compared with the control group children.

In our, study no statistically significant difference was seen in terms of height velocity $(p=0.313)$ and height velocity percentage $(p=0.576)$ comparing the test and control groups. Also, there was a statistically significant difference $(p=0.003)$ between the follow-up height of the test $(106.99 \mathrm{~cm})$ and control groups $(112.81 \mathrm{~cm})$, depicting no catch-up growth in terms of height. This can be attributed to the fact that linear growth does not begin until the child has achieved at least $85 \%$ of the expected weight for length (Walker and Golden, 1988). Also, Golden concluded that weight gain precedes height gain, ${ }^{30}$ thus explaining no catch-up growth in terms of height. Further studies incorporating a larger sample size and longitudinal evaluation are required to confirm the results of this study and to evaluate whether oral health has an impact on general health and well-being of the child.

\section{CONCLUSION}

Thus, it can be concluded that children with S-ECC have less weight and height as compared with other children with low caries. After dental rehabilitation, there was a significant improvement in the weight and height of S-ECC group children. The mean values of growth parameters were still higher in the control group as compared with the S-ECC group; however, the difference in values was less as compared with baseline. Overall intergroup comparison after dental rehabilitation showed that S-ECC group no longer differed from the controls in relation to weight.

\section{REFERENCES}

1. Holm AK. Caries in the preschool child: international trends. J Dent 1990 Dec;18(6):291-295.

2. Subramaniam P, Prashanth P. Prevalence of early childhood caries in 8-48 month old preschool children of Bangalore City, South India. Contemp Clin Dent 2012 Jan;3(1):15-21.

3. AAPD: Definition of early childhood caries: classifications, consequences, and preventive strategies. Pediatr Dent Reference Manual 2012-2013;34:12-13.
4. Chawla HS, Gauba K, Goyal A. Trend of dental caries in children of Chandigarh over the last sixteen years. J Indian Soc Pedod Prev Dent 2000 Mar;18(1):41-45.

5. Gaur S, Nayak R. Underweight in low socioeconomic status preschool children with severe early childhood caries. J Indian Soc Pedod Prev Dent 2011 Oct-Dec;29(4):305-309.

6. Mahejabeen R, Sudha P, Kulkarni SS, Anegundi R. Dental caries prevalence among preschool children of Hubli: Dharwad city. J Indian Soc Pedod Prev Dent 2006 Mar;24(1):19-22.

7. Hong R. Effect of economic inequality on chronic childhood undernutrition in Ghana. Public Health Nutr 2007 Apr;10(4): 371-378.

8. Wang Y, Monteiro C, Popkin BM. Trends of obesity and underweight in older children and adolescents in the United States, Brazil, China and Russia. Am J Clin Nutr 2002 Jun;75(6): 971-977.

9. Moszynski P. Unicef warns of "epidemic" of childhood malnutrition. BMJ 2006 May 6;332(7549):1051.

10. Acs G, Shulmann R, Ng MW, Chussid S. The effect of dental rehabilitation on the body weight of children with early childhood caries. Pediatr Dent 1999 Mar-Apr;21(2):109-113.

11. Cunnion DT, Spiro A, Jones JA, Rich SE, Papageorgiou CP, Tate A, Casamassimo P, Hayes C, Garcia RI. Pediatric oral health-related quality of life improvement after treatment of early childhood caries: a prospective multisite study. J Dent Child (Chic) 2010 Jan-Apr;77(1):4-11.

12. Acs G, Pretzer S, Foley M, Ng MW. Perceived outcomes and parental satisfaction following dental rehabilitation under general anaesthesia. Pediatr Dent 2001 Sep-Oct;23(5): 419-423.

13. Kalra G, Bansal K, Sultan A. Prevalence of early childhood caries and assessment of its associated risk factors in preschool children of urban Gurgaon, Haryana. Indian J Dent Sci 2011; 3(2):12-16.

14. Virdi M, Bajaj N, Kumar A. Prevalence of severe early childhood caries in pre-school children in Bahadurgarh, Haryana, India. Internet J Epidemiol 2010;8(2).

15. Gruebbel AO. A measurement of dental caries prevalence and treatment service for deciduous teeth. J Dent Res 1944;23: 163-168.

16. How to calculate growth velocity. [Internet]. 2010. Available from: http:/ / www.ehow.com/how_6453983_calculate-growthvelocity.html.

17. Hallett KB, O'Rourke PK. Caries experience in preschool children referred for specialist dental care in hospital. Aust Dent J 2006 Jun;51(2):124-129.

18. Miller J, Vaughan-Williams E, Furlong R, Harrison L. Dental caries and children's weights. J Epidemiol Community Health 1982 Mar;36(1):49-52.

19. Acs G, Lodolini G, Shulman R, Chussid S. The effect of dental rehabilitation on the body weight of children with failure to thrive: case reports. Compend Contin Educ Dent 1998 Feb; 19(2):164-171.

20. Malek Mohammadi T, Wright CM, Kay EJ. Childhood growth and dental caries. Community Dent Health 2009 Mar;26(1): 38-42.

21. Acs G, Lodolini G, Kaminski S, Cisneros GJ. Effect of nursing caries on body weight in a pediatric population. Pediatr Dent 1992 Sep-Oct;14(5):302-305.

22. Low W, Tan S, Schwartz S. The effect of severe caries on the quality of life in young children. Pediatr Dent 1999 SepOct;21(6):325-326. 
23. Thomas CW, Primosch RE. Changes in incremental weight and well-being of children with rampant caries following complete dental rehabilitation. Pediatr Dent 2002 Mar-Apr; 24(2):109-113.

24. Filstrup SL, Briskie D, Fonseca M, Lawrence L, Wandera A, Inglehart MR. Early childhood caries and quality of life: child and parent perspectives. Pediatr Dent 2003 SepOct;25(5):431-440.

25. Anderson HK, Drummond BK, Thomson WM. Changes in aspects of children's oral-health-related quality of life following dental treatment under general anaesthetic. Int J Paediatr Dent 2004 Sep;14(5):317-325.
26. Ayhan H, Suskan E, Yildrim S. The effect of nursing or rampant caries on height, body weight and head circumference. J Clin Pediatr Dent 1996 Spring;20(3):209-212.

27. Sheiham A. Dental caries affects body weight, growth and quality of life in pre-school children. Br Dent J 2006 Nov 25;201(10):625-626.

28. Means RT, Krantz SB. Progress in understanding the pathogenesis of the anaemia of chronic disease. Blood 1992 Oct 1;80(7):1639-1647.

29. Falkner F. Velocity growth. Pediatrics 1973 Apr;51(4):746-747.

30. Waterlow JC. Relationship of gain in height to gain in weight. Eur J Clin Nutr 1994 Feb;48(Suppl 1):S72-S74. 